\title{
EKSPEKTASI SOSIAL PEMUDA SASAK DALAM NASYID YA FATA SASAK KARYA HAMZANWADI
}

\author{
SOCIAL EXPECTATION OF SASAK TEENAGER \\ IN NASYID YA FATA SASAK BY HAMZANWADI
}

\author{
Akhyar Rosidi \\ Universitas Hamzanwadi \\ zulmanan27@gmail.com
}

\begin{abstract}
Abstrak
Penelitian ini bertujuan untuk menguraikan ekspektasi sosial pemuda Sasak dalam nasyid $Y a$ Fata Sasak karya T.G.K.H. Muhammad Zainuddin Abdul Madjid (Hamzanwadi). Metode menelitian yang digunakan adalah semiotika yang bersifat kualitatif interpretatif dengan teknik analisis isi (content analysis) yang memfokuskan penelitian pada isi laten naskah nasyid Ya Fata Sasak sebagai data penelitian. Teknik ini dilakukan dengan cara menyalin naskah nasyid Ya Fata Sasak ke bahasa Indonesia, membaca, mencatat, dan melakukan pengkodean ke dalam lima kode Rolan Brthes seperti kode hermeneutik, kode aksi, kode simbolik, kode semantik, dan kode refrensial sehingga menentukan ekspektasi sosial pemuda Sasak. Hasil penelitan ini menunjukan bahwa, pemuda Sasak memiliki kesempatan yang sama dengan pemuda-pemuda lain yang ada di Indonesia untuk melakukan ekspektasi baik secara individu mamupun kelompok (kolektif). Setiap ekspektasi sosial yang dilakukan oleh pemuda Sasak tentunya berkaitan dengan kepentingan rakyat, bangsa, dan negara yang direalisasikan melalui penguatan wacana kritis dan independen untuk mempertahankan idialismenya, seperti membangun rasa percaya diri (penguatan karakter) dan menjalankan nilai-nilai sosial dan agama sebagai benteng persaudaraan dan persatuan, mengelola sumber daya alam agar mampu dimanfaatkan secara maksimal, ikut serta dalam berbagai kompetisi atau kontestasi, dan menanamkan semangat nasionalisme sebagai salah satu dasar untuk mempertahankan dan memajukan bangsa Indonesia.
\end{abstract}

Kata Kunci: Nasyid Ya Fata Sasak, ekpektasi sosial, Sasak, semiotika Rolan Barthes

\begin{abstract}
This study aims to describe the youth's social expectations of the nasyid text Sasak by T.G.K.H. Muhammad Zainuddin Abdul Majid. The research method used is semiotic that is qualitative interpretive with content analysis techniques that focus to the research on the latent content of nasyid text $Y a$ Fat Sasak as data research on the latent content of the nasyid Ya Fata Sasak research. This technique is carried out by copying the nasyid Ya Fata Sasak manuscript to Indonesian, reading, writing, and coding into five codes of Rolands Barthes such as hermeneutic code, action code, symbolic code, semantics code, and referential code. So the social expectations of the Sasak youth are defined. The result of this research shows that Sasak youth have equal opportunities with other young people in Indonesia to expect both individually and collectively. Every social expectation carried out by Sasak youth is certainly related to the interest of the people, nation and the state which is realized through the strengthening of critical and independent discourses to maintain their idealism, such as building self-confidence (character building) and carrying out social and religious values as brotherhood and unity, managing natural resources that can be utilized optimally, participating in various competitions of contestations, and instilling a
\end{abstract}


spirit of nationalism as the one of foundations for maintaining and advancing the Indonesian people.

Keywords: Nasyid Ya Fata Sasak, Sasak, social expectations, Roland Barthes' semiotics

\section{PENDAHULUAN}

Dewasa ini, karya sastra selalu ditempatkan pada posisi penting. Para ahli atau kritikus, akademisi, dan peminat sastra seringkali menganalisisnya. Berbagai pendekatan ditawarkan untuk mendapatkan hasil yang diinginkan misalnya, pendekatan sosiologi sastra, semiotika, dan lain-lain. Secara etimologi, kata sastra berasal dari bahasa Sanskerta; akar kata sas-, dalam kata kerja turunan berarti mengarahkan, mengajar, memberi petunjuk atau intruksi. Dengan demikian sastra dapat diartikan sebagai alat untuk mengajar, buku petunjuk, buku intruksi, atau pengajaran Teeuw (dalam Wijaya dan Al-Pansori, 2014: 1). Karya sastra merupakan hasil kreativitas pengarang yang bersifat imajinasi, dibentuk berdasarkan potret kehidupan, berupa peristiwa atau problem kehidupan yang mencakup hubungan antara manusia dengan alam, manusia dengan manusia, dan manusia dengan Tuhannya. Berbagai macam karya sastra (gendre sastra) telah ditawarkan, seperti puisi yang terdiri dari beberapa bentuk, salah satunya adalah nasyid yang tergolong sebagai folklor lisan dalam bentuk puisi rakyat.

Nasyid digunakan sebagai media dakwah oleh sebagian kalangan, seperti T.G.K.H. Muhammad Zainuddin Abdul Madjid_dikenal juga dengan sebutan Hamzanwadiyang terkenal sebagai pendidik, pendakwah, dan sastrawan. Lewat nasyidnya yang berjudul Ya Fata Sasak, ia menyelipkan inspirasi dan motivasi perjuangan kepada pemuda Sasak untuk melakukan sebuah perubahan (ekspektasi) dari perbuatan negatif seperti pergaulan bebas, minuman keras, mencuri, dan lain-lain. Ekspektasi yang semestinya dilakukan adalah membela kepentingan rakyat, bangsa, dan negara sesuai dengan amanah pancasila dan UUD 1945, melakukan penguatan wacana kritis dan independen untuk mempertahankan idialismenya, seperti membangun rasa percaya diri (penguatan karakter) dan menjalankan nilai-nilai keagamaan sebagai benteng persatuan, mengelola sumber daya alam agar mampu dimanfaatkan secara maksimal (penguatan ekonomi rakyat), ikut serta dalam berbagai kompetisi atau kontestasi, dan menanamkan semangat nasionalisme sebagai salah satu dasar mempertahankan dan memajukan bangsa Indonesia.

Nasyid tersebut merupakan karya sastra yang tidak cukup dibaca atau dinikmati saja, melainkan perlu mendapatkan tanggapan ilmiah untuk mengetahui pesan melalui tanda-tanda (bahasa) yang tersembunyi. Oleh karena itu, meneliti atau menganalisis nasyid Ya Fata Sasak yang belum pernah satu pun orang menelitinya secara khusus dan tidak hanya dinilai sebagai sebuah inspirsi dan motivasi perjuangan, namun memiliki ekspektasi pergerakan dan semangat nasionalisme yang harus dilakukan pemuda Sasak untuk mempertahankan, memajukan, dan menjaga keutuhan Negara Kesatuan Rebuplik Indonesia (NKRI) mejadi suatu hal yang menarik untuk diungkap. Berdasarkan hal tersebut, untuk memahami tanda dan mendapatkan jawaban ekspektasi sosial dan relevansinya dalam kehidupan pemuda 
Sasak yang sekaligus menjadi fokus dalam penelitian ini, tentu dengan memaknai teksnya secara mendetail, kemudian merekonstruksi dengan cara menempatkan leksia-leksia ke dalam lima kode semiotik Roland Barthes. Roland Barthes dalam teorinya menawarkan lima kode untuk memperoleh makna dari sebuah teks, yaitu kode hermeneutik, kode aksi, kode simbolik, kode semantik, dan kode kultural. Dengan memanfaatkan kelima kode tersebut, peneliti berharap mendapatkan jawaban dari apa yang peneliti pertanyakan sehingga bermanfaat baik secara teoritis maupun praktis.

\section{METODE PENELITIAN}

Penelitian ekspektasi sosial pemuda Sasak dalam nasyid Ya Fata Sasak karya Hamzanwadi ini dilakukan dengan menggunakan metode semiotika. Fokus penelitian dalam metode tersebut adalah tanda dan teks sebagai objek analisis (content analysis). Hoed (dalam Nurgiyantoro, 2013: 67) mengatakan, bahwa semiotika adalah ilmu atau metode analisis untuk mengkaji tanda yang bersifat kualitatif interpretatif. Penelitian kualitatif interpretatif ini dimaknai sebagai penelitian yang melakukan pengamatan dan menafsirkan tanda-tanda yang ada di dalam karya sastra. Jenis dan metode dalam penelitian ini selanjutnya dikaitkan berdasarkan teori Roland Barthes dengan cara menyalin teks nasyid Ya Fata Sasak ke dalam bahasa Indonesia, membaca secara berulang-ulang untuk memahami serta memaknai keseluruhan isi nasyid tersebut, memotong-motong leksia untuk menentukan kode dalam leksia, mencari hubungan antar leksia, mengumpulkan atau menyatukan kode, dan menyimpulkan makna dari setiap kode yang berhipogram. Dengan demikian peneliti dapat memahami dan menafsirkan teks tersebut secara menyeluruh berdasarkan metode dan teori semiotika Barthes sebagai jawaban atas pertanyaan di dalam penelitian ini.

\section{HASIL DAN PEMBAHASAN}

Langkah pertama yang dilakukan setelah analisis data adalah melakukan pemenggalan teks nasyid Ya Fata Sasak ke dalam satuan-satuan pembaca (lexias). Berdasarkan hasil pemenggalan, terdapat 11 leksia yang diperoleh dari judul dan jumlah larik (baris). Selanjutnya dikelompokan ke dalam lima kode Roland Barthes seperti kode hermeneutik, aksi, simbolik, semantik, dan referensial di bawah ini.

Pemuda Sasak (1)

Marilah nyanyikan nasyid kita Hai

pemuda Sasak Indonesia (2)

Sampaikanlah siang dan malam

Bahwa kita adalah saudara yang sejati (3) Semua

kita taat pada janji (4)

Maka minta perlindungan dan pertolonganlah dengan menghidupkan hizib kita (5)

Janganlah janganlah janganlah janganlah kita peduli

Janganlah janganlah janganlah janganlah kita bosan (6) Siapa

saja yang bercita-cita mencapai ketinggian

Ia tidak akan pernah takut terhadap musuh-musuh (7)

Indonesia (8)

Engkaulah simbol persatuan 
Hai jiwa dan ragaku (9)

Sasak adalah bagian dari Indonesia

Majulah ke depan jangan kau perdulikan! (10)

Jiwa dan ragaku adalah tebusan bagimu (wahai Indonesia) $2 \mathrm{X}$

\begin{tabular}{|c|c|c|}
\hline ساسك & فتى & يا \\
\hline sasak & fata & ya \\
\hline sasak & pemuda & hai \\
\hline
\end{tabular}

\section{Kode: J/HER. P, J/HER. PM, dan J/SIM}

\begin{tabular}{|c|c|c|c|c|c|c|c|}
\hline ودنبانيس & ساسك & فتى & * & نا & نشيد & اونغ & هيا \\
\hline $\mathrm{i}$ Inc & sasak & fata & ya & na & nasyid & ganu & hayya \\
\hline donesia & sasak & pemuda & hai & kita & nasyid & nyanyikan & maril \\
\hline
\end{tabular}

Hai pemuda sasak Indonesia $\quad$ Marilah nyanyikan nasyid kita

Kode: L 1-2/HER. PM, L 1-2/AKS KOL, L 1-2/SEM, dan L 1-2/REF

\begin{tabular}{|c|c|c|c|}
\hline الليالى & $g$ & مايلا| & بلغ \\
\hline layalia & wal & ayyama & ballighil \\
\hline malam & dan & siang & sampaikanlah \\
\hline
\end{tabular}

Sampaikanlah siang dan malam

Kode: L 3-4/HER. PM dan L 3-4/AKS KOL

\begin{tabular}{|c|c|c|c|c|c|}
\hline الوف & على & * كلنا & الصفا & ناوخا & نحن \\
\hline afa & 'alal & kulluna & sshafa & ikhwanu & nahnu \\
\hline anji & taat pada & semua kita & yang sejati & adalah saudara & bahwa kita \\
\hline
\end{tabular}

Semua kita taat pada janji

Kode: L 5/HER. P

Bahwa kita adalah saudara yang sejati

\begin{tabular}{|c|c|c|}
\hline يحى & بحزبنا & فاستعذ \\
\hline yahya & bihizbina & fasta'idz \\
\hline pertolongan & dengan menghidupkan hizib kita & maka minta perlindungan \\
\hline
\end{tabular}

Maka minta perlindungan dan pertolonganlah dengan menghidupkan hizib kita

Kode: L 6/HER. JP, L 6/AKS KOL, L6/SIM, dan L 6/REF

\begin{tabular}{|c|c|c|c|c|c|c|c|c|c|}
\hline نمالى & $y$ & $y$ & ע & $y *$ & نبالى & $y$ & $y$ & $y$ & $y$ \\
\hline numali & la & la & la & la & nubali & la & la & la & la \\
\hline kita bosan & & & & janganlah $4 \mathrm{x}$ & kita peduli & & & & janganlah $4 \mathrm{x}$ \\
\hline \multicolumn{5}{|c|}{ Janganlah 4X kita bosan } & \multicolumn{5}{|c|}{ Janganlah 4X kita peduli } \\
\hline
\end{tabular}

\section{Kode: L 7-8/AKS PERLA}

\begin{tabular}{|c|c|c|c|c|c|}
\hline موصرخ & من & * لايخشى & للمعالى & يسعى & من \\
\hline khusumi & $\min$ & la yakhsya & lil ma’ali & yas'a & man \\
\hline $\begin{array}{l}\text { musuh- } \\
\text { musuh }\end{array}$ & $\begin{array}{l}\text { takut } \\
\text { terhadap }\end{array}$ & $\begin{array}{l}\text { ia tidak akan } \\
\text { pernah }\end{array}$ & $\begin{array}{l}\text { mencapai } \\
\text { ketinggian }\end{array}$ & $\begin{array}{l}\text { bercita- } \\
\text { cita }\end{array}$ & $\begin{array}{ll}\text { siapa } & \text { saja } \\
\text { yang } & \end{array}$ \\
\hline $\begin{array}{l}\text { Ia tidak } \\
\text { musuh-m }\end{array}$ & kan pernal & takut terhadap & $\begin{array}{l}\text { Siapa saja } \\
\text { ketinggian }\end{array}$ & ang berc & ta mencapai \\
\hline
\end{tabular}

ودذانيسيا 


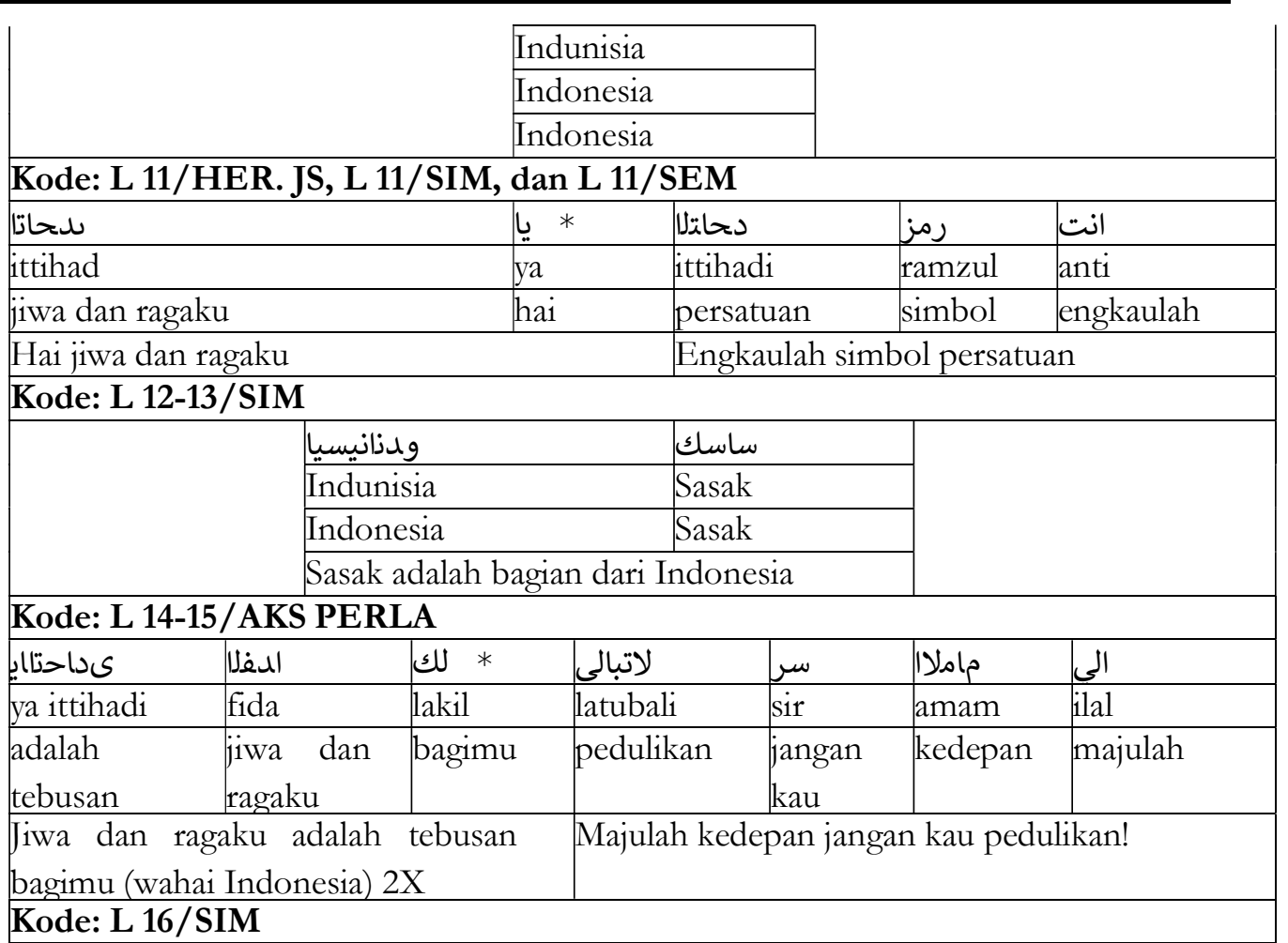

Ket.

J: Judul

L: Larik (baris)

1. HER: Kode Hermeneutik
a. P: Pentemaan
b. PM: Pengusulan Masalah
c. Pengacuan
d. Jebakan
e. PJ : Penundaan Jawaban
f. JS: Jawaban Sebagian
g. JP: Jawaban Penuh

2. AKS: Kode Aksi

a. AKS KOL: Aksi Kolektif

b. AKS PERLA: Aksi Pelawanan

3. SIM: Simbolik

4. SEM: Semantik

5. REF: Refrensial

Berdasarkan penjelasan di atas, maka dapat diuraikan sebagaimana penulis (Hamzanwadi) sebagai wakil kolektif pemuda Sasak terus memberikan ekspektasi dan motivasi perjuangan yang dituangkan dalam nasyid Ya Fata Sasak. Pemuda Sasak diharapkan mampu berekspektasi dalam segala hal, terutama dalam menjalankan nilai-nilai agama, sosial, dan budaya demi kepentingan rakyat, bangsa, dan negara. Ekspektasi dimaknai sebagai harapan besar yang diamanahkan kepada pemuda Sasak ini tentunya harus mampu 
membawa perubahan kearah yang lebih baik, sehingga tida ada lagi perbuatan-perbuatan buruk yang dilakukan oleh pemuda Sasak seperti, pergaulan bebas yang mengakibatkannya sebagi peminum minuman beralkohol, mengkonsumsi narkoba, pengedar narkoba, dan lain-lain. uraian-uraian tersebut dapat dijelaskan sebagaimana pengelompokan lima kode Roland Barthes dibawah ini.

\section{Kode Hermeneutik}

Kode hermeneutik merupakan kode dimana enigma (teka-teki) dapat dibedakan, diusulkan diformulasikan, dan akhirnya diungkapkan Barthes (dalam Lantowa dkk 2017: 142) sebagaimana leksia berikut.

(3) Sampaikanlah siang dan malam. Bahwa kita adalah saudara yang sejati (L 3-4/HER. PM/hal.8)

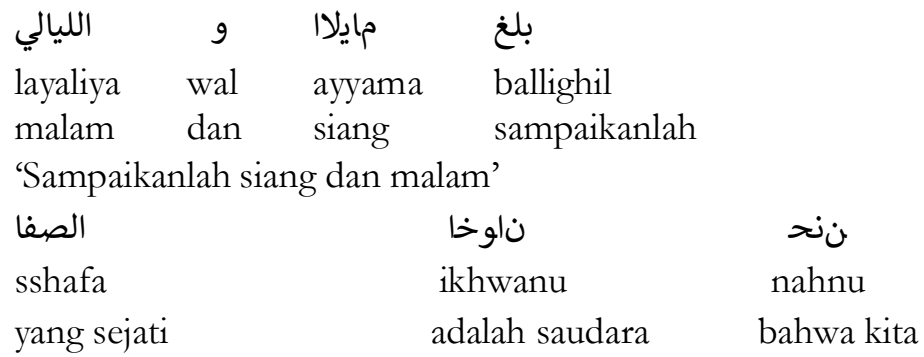

'Bahwa kita adalah saudara yang sejati'

Sampaikanlah siang dan malam. Babwa kita adalah saudara yang sejati (L 3-4/HER. PM/hal.8)

Seruan kepada semua orang khususnya pemuda Sasak untuk menyampaika persatuan dan persaudaraan. Leksia ini mengusulkan adanya masalah dibenak pembaca "bahwa kita adalah saudara yang sejati mengindikasikan adanya keadaan atau situasi yang menyebabkan seruan ini sangat penting untuk disampaikan antara siang dan malam.

\section{(4) Semua kita taat kepada janji (L 5/HER. PM/hal.8)}

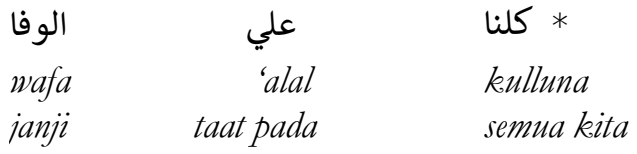

Semua kita taat pada janji (L 5/HER. PM/ hal.8)

Ditujukan kepada pemuda Sasak supaya mentaati janji atau kesepakatan yang telah disepakati. Leksia ini memberikan ruang kepada pembaca untuk mempertanyakan atau mengusulkan masalah, yaitu janji apa saja yang harus ditaati oleh pemuda Sasak.

(5) Maka minta perlindungan dan pertolonganlah dengan menghidupkan hizib kita (L 6/HER.JP/hal.8)

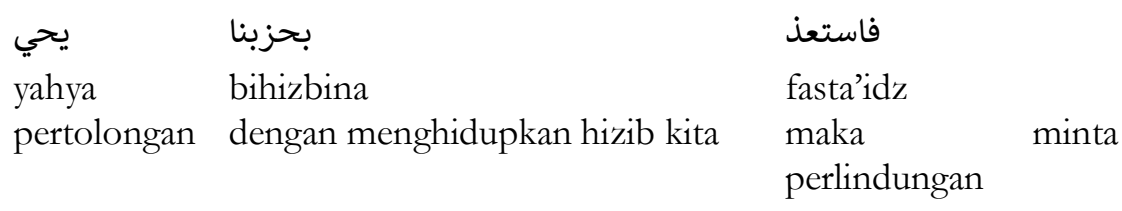


"Maka minta perlindungan dan pertolonganlah dengan mengbidupkan

bizib kita" (L 6/HER. JP/hal.8)

Seruan atau ajakkan bagi siapa pun khususnya pemuda Sasak yang menginginkan pertolongan, keselamatan, keberkahan, keberhasilan, dan kebaikan tentunya dengan cara membaca, memahami, dan mengamalkan hizib. Hizib yang dimaksud disini adalah hizib Nahdlatul Wathan (NW). Hizib NW merupakan kumpulan doa-doa yang dihimpun dari ayat-ayat suci al-quran, ma'tsurat nabawiyyah, doa para auliya, serta karangan dari Hamzanwadi sendiri. Leksia ini murupakan jawaban penuh dari seluruh permasalahanpermasalahan yang ada di dalam teks, yakni baik secara individu maupun kelompok pemuda Sasak semestinya melakukan penguatan kritis dan independen untuk mempertahankan idealismenya, seperti membangun rasa percaya diri (penguatan karakter), menyerukan dan menjalankan nilai-nilai keagamaan sebagai benteng persatuan dan persaudaraan, mengelola sumber daya alam agar mampu dimanfaatkan secara maksimal, dan memiliki semangat nasionalisme untuk mempertahankan dan memajukan bangsa Indonesia.

\section{Kode Aksi}

Kode aksi merupakan kode yang menjamin bahwa apa yang dibaca merupakan sebuah cerita, yaitu serangkaian aksi-aksi yang saling berkaitan antara satu dengan lainnya Lantowa dkk (2017: 163) sebagaimana leksia berikut.

(6) Janganlah janganlah janganlah janganlah kita peduli. Janganlah janganlah janganlah janganlah kita bosan (L 7-8/AKS/hal.8)

\begin{tabular}{|c|c|c|c|c|c|c|c|c|c|}
\hline نمالى & $y$ & $y$ & $y$ & $y *$ & نبالى & $y$ & $y$ & $y$ & ע \\
\hline numali & la & la & la & la & nubali & la & la & la & la \\
\hline kita bosan & & & & janganlah 4x & $\begin{array}{l}\text { kita } \\
\text { peduli }\end{array}$ & & & & $\begin{array}{l}\text { jangan } \\
\text { lah } 4 \mathrm{x}\end{array}$ \\
\hline \multicolumn{5}{|c|}{ Janganlah 4X kita bosan } & \multicolumn{5}{|c|}{ Janganlah 4X kita peduli } \\
\hline \multicolumn{10}{|c|}{$\begin{array}{l}\text { Janganlah janganlah janganlah janganlah kita peduli. Janganlah janganlah } \\
\text { janganlah janganlah kita bosan (L 7-8/AKS/ hal.8) }\end{array}$} \\
\hline
\end{tabular}

Leksia ini menegaskan tentang adanya perlawanan. Perlawanan yang dimaksud, misalnya melawan keegoisan, kesombongan, ketakutan, kecemasan dan lain-lain yang ada di dalam individu itu sendiri serta pengaruh luar. Segala hal tersebut seharusnya mampu dilawan.

(7) Siapa yang bercita-cita mencapai ketinggian. Ia tidak akan pernah takut terhadap musuh-musuh (L 9-10/AKS PERLA/hal.8)

\begin{tabular}{|c|c|c|c|c|c|}
\hline موصرخ| & من & * لايخشى & للمعالى & يسعى & من \\
\hline khusumi & $\min$ & la yakhsya & lil ma'ali & yas'a & $\operatorname{man}$ \\
\hline $\begin{array}{l}\text { musuh- } \\
\text { musuh }\end{array}$ & $\begin{array}{l}\text { takut } \\
\text { terhadap }\end{array}$ & $\begin{array}{l}\text { ia tidak } \\
\text { akan pernah }\end{array}$ & $\begin{array}{l}\text { mencapai } \\
\text { ketinggian }\end{array}$ & $\begin{array}{l}\text { bercita- } \\
\text { cita }\end{array}$ & $\begin{array}{l}\text { siapa saja } \\
\text { yang }\end{array}$ \\
\hline \multicolumn{3}{|c|}{$\begin{array}{l}\text { Ia tidak akan pernah takut terhadap } \\
\text { musuh-musuh }\end{array}$} & \multicolumn{3}{|c|}{$\begin{array}{l}\text { Siapa saja yang bercita-cita } \\
\text { mencapai ketinggian }\end{array}$} \\
\hline
\end{tabular}


Siapa yang bercita-cita mencapai ketinggian. Ia tidak akan pernab takut terbadap musub-musub (L 9-10/ AKS PERLA/hal.8)

Bagi siapa pun yang melakukan ekspektasi khususnya pemuda Sasak tidak seharusnya takut terhadap proses dan lawan (pesaing). Anggaplah semua itu menjadi langkah awal untuk mencapi ekspektasi. Leksia ini menunjukan adanya perlawanan bagi siapa pun yang menghalangi perjuangan.

(10) Sasak adalah bagian dari Indonesia. Majulah ke depan jangan kau pedulikan (L 14-15/AKS PERLA/hal.8)

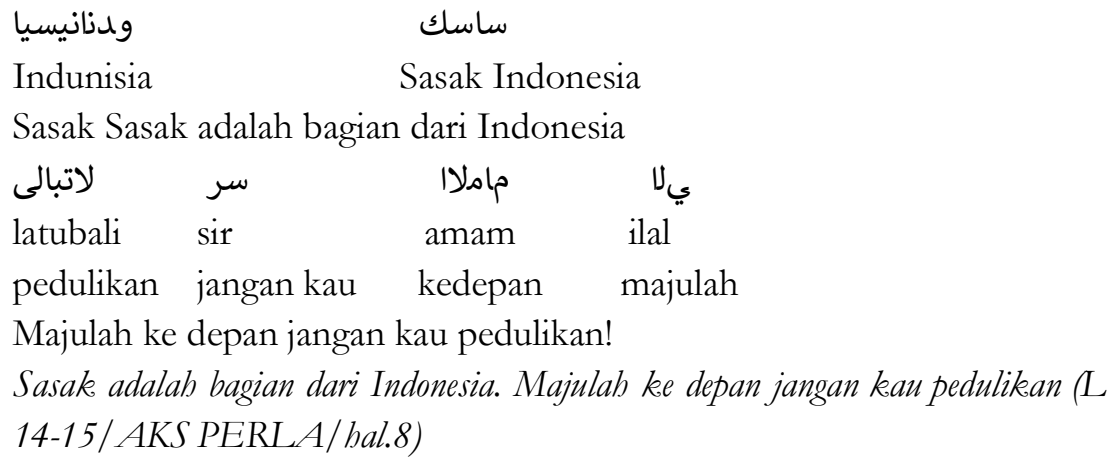

Suku sasak (pemuda Sasak) adalah bagian dari rakyat Indonesia yang memiliki hak dan kesempatan yang sama dengan orang lain untuk terus berkontribusi melakukan suatu hal yang baik untuk bangsa Indonesia. Leksia ini menunjukan adanya perlawanan kepada siapa pun yang menghalangi langkah perjuangan seperti penjelasan pada leksia (5) dan (7).

\section{Kode Simbolik}

Kode simbolik adalah tempat di mana kode-kode memiliki banyak tempat dan saling bertukar tempat Barthes (dalam Lantowa dkk 2017: 171) sebagaimana leksia dibawah ini.

(1) Pemuda Sasak (J/SIM/hal.8)

\begin{tabular}{|c|c|c|}
\hline ساسك & فتى & يا \\
\hline Sasak & fata & $y$ \\
\hline Sasak & pemuda & $\mathrm{h}$ \\
\hline
\end{tabular}

Pemuda Sasak merupakan simbol yang tergolong sebagai masyarakat berumur 1530 tahun, berdasarkan UU Kepemudaan No 40 Tahun 2009. Dalam hal ini tidak hanya dilihat dari segi umur, akan tetapi menekankan pada semangat dan perjuangan yang semestinya ia lakukan baik secara kolektif maupun individu untuk mencapai harapan (ekspektasi), seperti 1) membela kepentingan rakyat, bangsa, dan negara sesuai dengan amanah pancasila dan UUD 1945, 2) melakukan penguatan wacana kritis dan independen untuk mempertahankan idialismenya, seperti membangun rasa percaya diri (penguatan karakter) dan menjalankan nilai-nilai keagamaan sebagai benteng persatuan, 3) mengelola sumber daya alam agar mampu dimanfaatkan secara maksimal (penguatan ekonomi rakyat), 
4) ikut serta dalam berbagai kompetisi atau kontestasi, dan 5) menanamkan semangat nasionalisme sebagai salah satu dasar untuk mempertahankan dan memajukan bangsa Indonesia.

(9) Engkaulah sumber persatuan. Hai jiwa dan ragaku (L 12-13/SIM/hal.8)

\begin{tabular}{|c|c|c|c|c|}
\hline ل & * & | دحاتل| & رمز & انت انت \\
\hline ittihad & ya & ittihadi & ramzul & anti \\
\hline jiwa dan ragaku & hai & persatuan & simbol & engkaulah \\
\hline Hai jiwa dan ragaku & & \multicolumn{3}{|c|}{ Engkaulah simbol persatuan } \\
\hline Fnoloulah sumbert & & abua & $3 / S I M$ & \\
\hline
\end{tabular}

Jiwa dan raga merupakan unsur utama bagi keberlangsungan hidup manusia yang membicarakan antara zohir dan batin. Leksia ini menjadikan jiwa dan raga sebagai sumber persatuan seperti yang terlihat pada leksia (8) yang memberikan pengertian bahwa persaudaraan dan persatuan tidak akan pernah tercapai tanpa adanya tindakan secara zohir dan batin dari setiap individu maupun kelompok (kolektif).

\section{Kode Semantik}

Barthes (dalam Lantowa dkk 2017: 174) mengatakan kode semantik merupakan kode yang menunjuk pada sebuah karakter atau sebuah tempat atau sebuah objek tertentu dalam teks sebagaimana leksia berikut.

\section{(8) Indonesia (L 11/SEM/hal.8)}

$$
\text { ودنانيسيا }
$$

Indunisia

Indonesia

Indonesia (L 11/SEM/hal.8)

Indonesia adalah negara yang memiliki keberagaman keberagaman dengan populasi penduduk terbesar keempat di dunia. Leksia ini jelas menggambarkan tentang keadaan Indonesia yang kaya akan keberagaman tersebut, sehingga perbedaan-perbedaan yang ada disatukan dengan adanya Negara Kesatuan Repoblik Indonesia (NKRI).

\section{(11) Jiwa dan ragaku adalah tebusan bagimu (L 16/SEM/hal.8)}

\begin{tabular}{|c|c|c|}
\hline ىداحتااي & الدفلا & * لك * \\
\hline ya ittihadi & fida & lakil \\
\hline $\begin{array}{l}\text { adalah tebusan } \\
\text { Jiwa dan ragaku }\end{array}$ & $\begin{array}{l}\text { jiwa dan ragaku } \\
\text { adalah tebusan } b\end{array}$ & $\begin{array}{l}\text { bagimu } \\
\text { hu (wahai Indonesia }\end{array}$ \\
\hline
\end{tabular}

Jiwa dan raga tidak akan pernah terpisahkan dari yang namanya manusia. Leksia ini memiliki keterkaitan antara leksia (8) dan (9) tentang simbol persaudaraan dan persatuan adalah jiwa dan raga yang dibingkai dalam Negara Kesatuan Republik Indonesia (NKRI). 


\section{Kode Referensial}

Kode referensial adalah penanda-penanda yang merujuk pada seperangkat refrensi atau pengetahuan umum yang mendukung teks Lantowa dkk (2017: 181) sebagaimana leksia berikut.

(2) Marilah nyanyikan nasyid kita. Hai pemusa Sasak Indonesia (L 1-2/AKS/hal.8)

\begin{tabular}{|c|c|c|c|c|c|c|}
\hline ول ونبانيسيا & فتى ساسك & * & نا & 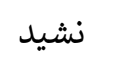 & اونذ اون & هيا \\
\hline bi Indunisia & sasak & ya & na & nasyid & ganu & hayya \\
\hline Indonesia & pemuda & hai & kita & nasyid & nyanyikan & marilah \\
\hline \multicolumn{2}{|c|}{ Hai pemuda sasak Indonesia } & \multicolumn{5}{|c|}{ Marilah nyanyikan nasyid kita } \\
\hline $\begin{array}{l}\text { Marilah } \\
\text { / AKS }\end{array}$ & kan nasyid kit & & & & . & 1 - \\
\hline
\end{tabular}

Seruan atau pangilan untuk menyanyikan nasyid secara kolektif, diperuntukkan kepada pemuda Sasak yang menjadi bagian dari rakyat Indonesia. Leksia ini menggambarkan tentang karya sastra. Karena sebagaimana yang diketahui, nasyid dikategorikan sebagai folklor lisan dalam bentuk puisi rakyat yang dituangkan melalui media bahasa. Hal inilah yang menjadikan nasyid perlu dipahami baik dari segi makna yang dikaitkan dengan realita kehidupan yang terkandung di dalamnya dengan cara menganalisis mengunakan berbagai macam pendekatan sastra.

\section{SIMPULAN}

Penelitian ini menemukan 11 leksia yang diperoleh dari judul dan jumlah larik (baris). Ekspektasi sosial pemuda Sasak yang semestinya ia lakukan seperti 1) membela kepentingan rakyat, bangsa, dan negara sesuai dengan amanah pancasila dan UUD 1945, 2) melakukan penguatan wacana kritis dan independen untuk mempertahankan idialismenya, seperti membangun rasa percaya diri (penguatan karakter) dan menjalankan nilai- nilai keagamaan sebagai benteng persatuan, 3) mengelola sumber daya alam agar mampu dimanfaatkan secara maksimal (penguatan ekonomi umat), 4) ikut serta dalam berbagai kompetisi atau kontestasi, dan 5) menanamkan semangat nasionalisme sebagai salah satu dasar untuk mempertahankan dan memajukan bangsa Indonesia.

\section{DAFTAR PUSTAKA}

Ekarina. 2018. "Pelari Asal NTB Raih Mendali Emas di Kejuaraan Atletik Dunia". Diunduh di https://katadata.co.id/berita/2018/07/12/pelari-asal-ntb-raih-medaliemas-di-kejuaraan-atletik-dunia tanggal 20 Aagustus 2018.

Lantowa, Jafar dkk. 2017. Semiotika Teori, Metode, dan Penerapannya dalam Penelitian Sastra. Yogyakarta: CV Budi Utama.

Nurgiyantoro, Burhan. 2013. Teori Pengkajian Fiksi. Yogyakarta: Gajah Mada University Press. 
Akhyar Rosidi

Universitas Hamzanwadi

Setiaji Prabowa, Danang. 2013. "Kategori Baru Disebut Pemuda Berdasar Umur yang Diusulkan Mempora”. Diunduh di http://www.tribunnews.com/nasional/2013/08/20/ini-kategori-baru-disebutpemuda-berdasar-umur-yang-diusulkan-menpora tanggal 01 Agustus 2018.

Wijaya, Herman dan Muh. Jaelani Al-Pansori. 2014. Konsep Dasar Sastra Teori dan Aplikasi. Yogyakarta : Multi Presindo. 